\title{
Does Mind-Wandering Relate to Mood and Stress in Young Adults? A Narrative Review
}

\author{
Gladys Sina', Vickie Plourde ${ }^{1,2}$ \\ ${ }^{1}$ Faculty Saint-Jean, University of Alberta, Edmonton, Alberta \\ 2 School of Psychology, University of Moncton, Moncton, New Brunswick \\ Corresponding author: gsina@ualberta.ca
}

\section{ABSTRACT}

Mind-wandering (MW) is ubiquitous and has been extensively studied in young adults. Studies have shown that MW, daydreaming, and sluggish cognitive tempo symptoms (SCT; e.g., staring, mental fogginess, confusion, hypoactivity, sluggishness, lethargy, and drowsiness) are interrelated constructs and all relate to mood and stress-related symptoms. The aims of the current review are to a) document the associations between MW (and related constructs: daydreaming, and SCT) and mood/stress-related symptoms (e.g., anxiety and depression symptoms) in young adults and b) identify potential mechanisms underlying these relationships. We conducted a narrative review of the literature on the subject. We searched MEDLINE (Ovid) and PsycINFO ${ }^{\circledR}$ (Ovid) databases and performed duplicate and independent screening. A total of 559 unique records were identified, and 22 records (published between 1978 and 2017) were included. We confirmed existing evidence of the associations between MW, daydreaming, SCT and mood/stress-related symptoms in young adults (aged 18 - 30 years). Although these associations are reported, our understanding of its directionality and underlying mechanisms remains incomplete. These findings highlight the need for further research combining experimental and correlational designs and including possible mechanisms of these associations in this population.

\section{Introduction}

The experience of mind-wandering $(\mathrm{MW})$ is so common that it permeates every human's life. Indeed, unrelated thoughts have been shown to occupy, on average, $30-50 \%$ of our waking conscious experience (Klinger, 1999; Kane et al., 2007; Killingsworth \& Gilbert, 2010; Franklin, Smallwood, \& Schooler, 2011). Beneficial outcomes of MW have been studied and described elsewhere (Baird, Smallwood, \& Schooler, 2011; Smallwood, 2013;
Smallwood, Ruby, \& Singer, 2013), including effective problem-solving (Poerio, Totterdell, \& Miles, 2013), creativity (Dunn, Corn, \& Morelock, 2004), and motivation to strive for one's goals (Meyer, Finucane, \& Jordan, 2011). However, less positive effects have also been investigated, such as interference with demanding cognitive tasks (e.g., reading, driving; Mooneyham \& Schooler, 2013) and associations between high levels of MW and internalized 
processes like negative mood and stress (Smallwood, McSpadden, Luus, \& Schooler, 2008; Killingsworth \& Gilbert, 2010; Vinski \& Watter, 2013).

MW and daydreaming have been used as synonyms and defined as processes "involving attention becoming focused on mentation unrelated to the external environment or to any on-going task" (Singer, 1966). Although the distinction has been made between the two constructs in some questionnaires such as the Imaginal Processes Inventory (IPI; Singer \& Antrobus, 1963, 1972), both MW (e.g., "I am the kind of person whose thoughts often wander") and daydreaming frequency (e.g. "I lose myself in active daydreaming"), these scales are strongly correlated (Carciofo, Yang, Song, Du, \& Zhang, 2016; Cundiff \& Gold, 1979) and most studies interchangeably used the two terms. Therefore, MW and daydreaming will be used interchangeably in the present study, but they will be reported separately following how they were referred to in the included studies.

MW has also been studied with specific questionnaires evaluating trait levels or the individual's disposition to mind-wander (Mrazek, Phillips, Franklin, Broadway, \& Schooler, 2013) or using experience sampling (ES), wherein self-reports on participants' on-going experience are collected (Kahneman, Krueger, Schkade, Schwarz, \& Stone, 2004). The probe-caught method is an example of ES (Smallwood \& Schooler, 2006) whereby participants are periodically stopped during a task and asked to report the contents of their experience (Smallwood \& Schooler, 2015). Task-unrelated thoughts (TUTs) and task-related interference (TRI) fall under the broad umbrella conceptualization of MW (Smallwood, Riby, Heim, \& Davies, 2006). While TUTs are synonymous with MW, TRI refers to evaluative thoughts regarding how one is performing on a task (e.g., "I thought about how I should work more carefully" on the Dundee Stress State Questionnaire) (DSSQ; Matthews, Joyner, Gilliland, Huggins, \& Falconer, 1999). Even though TRI experiences are related to the task, they are not directly about responsiveness to task stimuli or demands. Therefore, TRI is characterized as MW about the task itself; one might monitor their performance on the task or mind-wander about tactics, for example.

The experience of mind-wandering (MW) is so common that it permeates every human's life. Indeed, unrelated thoughts have been shown to occupy, on average, $30-50 \%$ of our waking conscious experience (Klinger, 1999; Kane et al., 2007; Killingsworth \& Gilbert, 2010; Franklin, Smallwood, \& Schooler, 2011). Beneficial outcomes of MW have been studied and described elsewhere (Baird, Smallwood, \& Schooler, 2011; Smallwood, 2013; Smallwood, Ruby, \& Singer, 2013), including effective problem-solving (Poerio, Totterdell, \& Miles, 2013), creativity (Dunn, Corn, \& Morelock, 2004), and motivation to strive for one's goals (Meyer, Finucane, \& Jordan, 2011). However, less positive effects have also been investigated, such as interference with demanding cognitive tasks (e.g., reading, driving; Mooneyham \& Schooler, 2013) and associations between high levels of MW and internalized processes like negative mood and stress (Smallwood, McSpadden, Luus, \& Schooler, 2008; Killingsworth \& Gilbert, 2010; Vinski \& Watter, 2013).

MW and daydreaming have been used as synonyms and defined as processes "involving attention becoming focused on mentation unrelated to the external environment or to any on-going task" (Singer, 1966). Although the distinction has been made between the two constructs in some questionnaires such as the Imaginal Processes Inventory (IPI; Singer \& Antrobus, 1963, 1972), both MW (e.g., "I am the kind of person whose thoughts often wander") and daydreaming frequency (e.g., "I lose myself in active daydreaming"), these scales are strongly correlated (Carciofo, Yang, Song, Du, \& Zhang, 2016; Cundiff \& Gold, 1979) and most studies interchangeably used the two terms. Therefore, $\mathrm{MW}$ and daydreaming will be used interchangeably in the present study, but they will be reported separately following how they were referred to in the included studies. 
MW has also been studied with specific questionnaires evaluating trait levels or the individual's disposition to mind-wander (Mrazek, Phillips, Franklin, Broadway, \& Schooler, 2013) or using experience sampling (ES), wherein self-reports on participants' on-going experience are collected (Kahneman, Krueger, Schkade, Schwarz, \& Stone, 2004). The probe-caught method is an example of ES (Smallwood \& Schooler, 2006) whereby participants are periodically stopped during a task and asked to report the contents of their experience (Smallwood \& Schooler, 2015). Task-unrelated thoughts (TUTs) and task-related interference (TRI) fall under the broad umbrella conceptualization of MW (Smallwood, Riby, Heim, \& Davies, 2006). While TUTs are synonymous with MW, TRI refers to evaluative thoughts regarding how one is performing on a task (e.g. "I thought about how I should work more carefully" on the Dundee Stress State Questionnaire) (DSSQ; Matthews, Joyner, Gilliland, Huggins, \& Falconer, 1999). Even though TRI experiences are related to the task, they are not directly about responsiveness to task stimuli or demands. Therefore, TRI is characterized as MW about the task itself; one might monitor their performance on the task or mind-wander about tactics, for example.

MW and daydreaming have mainly been studied within experimental and cognitive psychology, treated as cognitive processes, and investigated in relation to daily activities and functioning. Interestingly, MW and daydreaming are also part of a wider construct named sluggish cognitive tempo (SCT), which has mostly been studied in clinical psychology. SCT is characterized by symptoms of excessive daydreaming, staring, mental fogginess or confusion, and slowed behaviour or thinking (Becker, Marshall, \& McBurnett, 2014). SCT is a correlated but independent construct from inattentive symptoms of attention deficit hyperactivity disorder (ADHD) (Becker, Garner, Tamm, Antonini, \& Epstein, 2019; Wood, Lewandowski, Lovett, \& Antshel, 2017). Although historically, some scholars have argued that SCT symptoms are a subset of ADHD symptoms (Carlson \& Mann, 2002), SCT symptoms appear to be separable from ADHD symptoms of inattention and hyperactivity (Carlson \& Mann, 2002). Additionally, SCT symptoms can be found in populations without ADHD (Wood, Lewandowski, Lovett, \& Antshel, 2017). Despite the conceptual relationships between SCT, $M W$, and daydreaming, they have rarely been studied together. Instead they grew in parallel over the last few decades.

It is becoming increasingly clear that these three constructs would benefit from being studied together, more so since recent research has provided empirical support to the idea that SCT plays a role in predicting MW (Ostojic, 2018). Other than their conceptual similarities, they all have in common their associations with mood and anxiety/stress-related symptoms. A large body of research has examined MW, daydreaming, and SCT symptoms in relation to mood, stress, and functional impairment. Among others, daydreaming has been associated with feeling depressed, increased vulnerability to hypomania (Meyer et al., 2011), negative affect (Carciofo, Song, Du, Wang, \& Zhang, 2017), psychological distress (Cuper \& Lynch, 2008), and greater risk for suicidality in individuals who daydream about violence and revenge (Selby, Anestis, \& Joiner, 2007). High levels of SCT symptoms have also been interrelated with psychological functioning. SCT symptoms have been demonstrated as predicting emotion dysregulation (Flannery, Becker, \& Luebbe, 2016), loneliness, lower self-esteem (Becker et al., 2018), suicidality (Selby et al., 2007), and overall functioning (Flannery, Luebbe, \& Becker, 2017). Previous studies have also demonstrated a co-occurrence between SCT, anxiety, and depression symptoms (Becker, Luebbe, Fite, Stoppelbein, \& Greening, 2014; Lee, Chang, Lin, \& Cheng, 2014; Willcutt et al., 2014; Wood et al., 2017).

However, to the best of our knowledge, no published review has exhaustively documented studies looking at MW, daydreaming, and SCT symptoms in relation to mood and anxiety/stress-related symp- 
toms. This review is much needed, especially in young adults, since: (1) SCT, MW, and daydreaming have mainly been studied with this population, and more specifically in college students; and (2) SCT seems to be particularly elevated during the adolescence and young adult developmental periods (Flannery et al., 2016; Leopold et al., 2016). Indeed, the prevalence of elevated SCT symptoms in adults has been estimated to be 5.8\% (Barkley, 2012) whereas, prevalence of $12-14 \%$ has been reported in samples of college students (Flannery et al., 2016; Jarrett, Siddiqui, Lochman, \& Qu, 2014; Wood et al., 2017).

Therefore, this study's main purpose was to conduct a narrative review combining these three constructs (SCT, MW and daydreaming), to identify their associations to mood and anxiety/stress-related symptoms in young adults. A secondary aim was to better understand the directionality and mechanisms underlying these associations.

\section{Methods}

Study inclusion and exclusion criteria:

Relevant studies were located based on the following criteria: (a) participants were between ages 18 and 30 years; (b) MW, daydreaming or SCT symptoms were measured using any method (e.g., self-report, thought probes, etc.); and (c) the study included measures of anxiety/stress-related and/ or depression and mood-related symptoms or states, using any method (e.g., self-report, mood or stress induction, etc.). Post-traumatic stress disorder was excluded because it does not fit this study's scope, given the major clinical distinctions between this diagnosis and other anxiety disorders (example: https://www.ncbi.nlm.nih. gov/pmc/articles/PMC5371751/\#sec2-behavsci-07-00007title). The following study designs were included: clinical or pre-clinical studies, cohort studies, randomized control trials, and experimental studies. Studies that did not specifically examine the relationship between SCT, MW, and daydreaming, and mood or anxiety/stress measures were excluded. Articles that were not writ- ten in English or French were also excluded. Review articles were excluded, but systematic reviews were flagged up for reviewing reference lists. Other than age, no restrictions were imposed on sex, race, or population (clinical and non-clinical, college students and nonstudents).

\section{Search strategy:}

In consultation with a librarian, the search strategy was developed and adapted for use in two databases. In June 2018, MEDLINE Ovid and PsycINFO Ovid were searched using the following key terms: 'sluggish cognitive tempo', 'sluggish tempo', 'slow cognitive tempo', 'mind wandering', 'daydream*', 'stress*', 'mood*', 'emotion*', 'internaliz*', 'anxiety', 'depression', and 'bipolar'. Search results of 230 (MEDLINE) and 456 (PsycINFO) articles were initially identified when combining keywords. After removing duplicates, 559 unique articles remained.

Study selection:

Following the initial search, we exported articles from the databases into an Excel file where titles and abstracts were screened for eligibility based on the inclusion/exclusion criteria described above. The search process was inspired by PRISMA (Moher et al., 2009). Following the title and abstract review, 45 studies were selected for full-text review. The primary (i.e., title/abstract) screening was independently performed by two reviewers (Author and Author). The secondary screening (i.e., full-texts) was performed by one reviewer (G.S.) and, when completed, was reviewed by the second author (V.P.). During the full-text review, 22 articles were chosen for final inclusion (Figure 1 displays the flow diagram). Any disagreements during the primary and secondary screenings were resolved between the two reviewers.

Data extraction \& synthesis:

The data was extracted by one reviewer (G.S.) for the included studies ( $n=22$ ), and a second reviewer (V.P.) verified the extracted data. Disagreements were resolved via discussion. The extracted information included author and year, study design, 


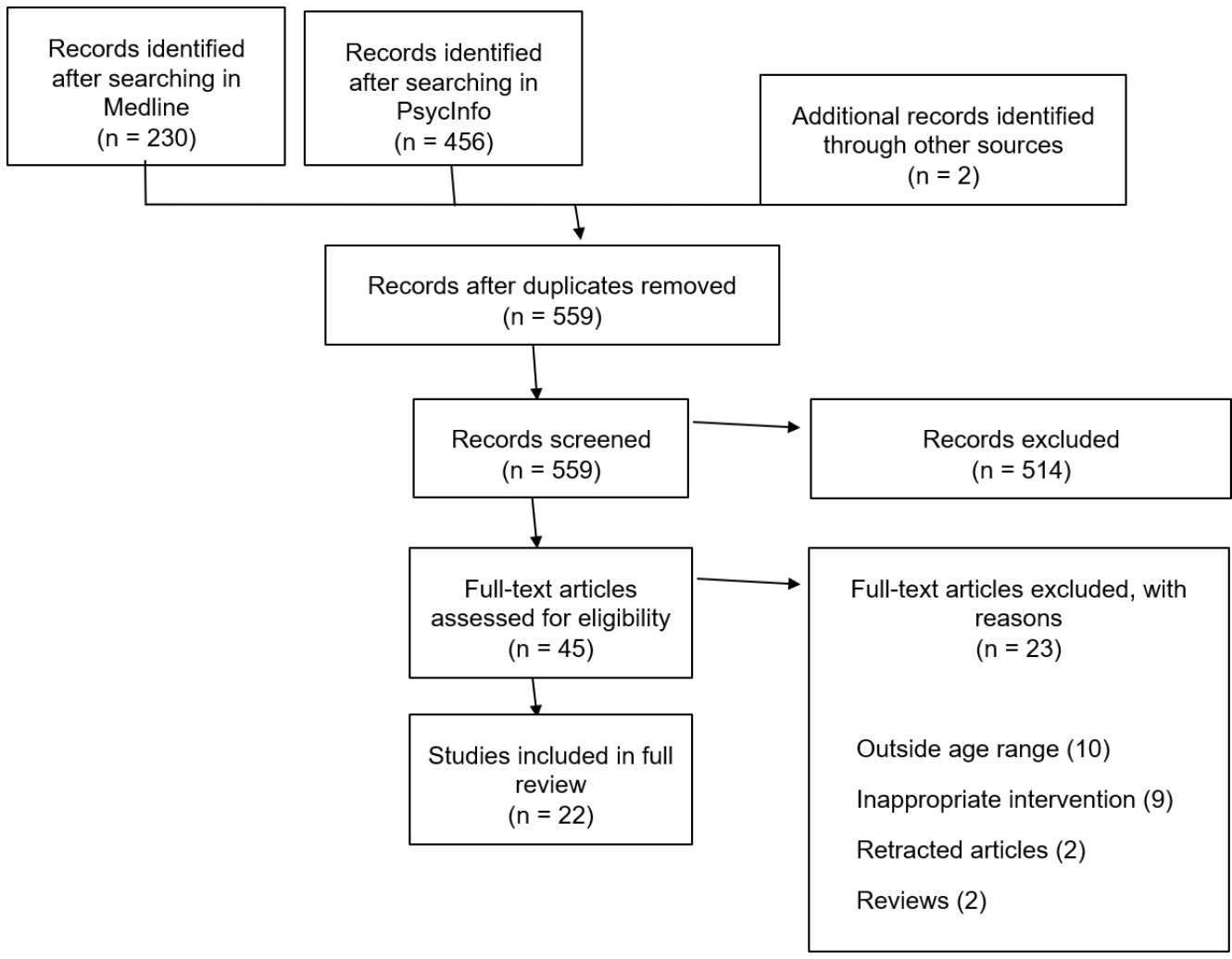

Figure 1. Flow Diagram. Adapted from Moher et al., 2009.

aims, population, and measured variables, divided into studies looking at MW (Table 1), daydreaming (Table 2) and SCT (Table 3). Three studies (Carciofo et al., 2016; Cundiff \& Gold, 1979; Giambra \& Traynor, 1978) looked separately at MW and daydreaming scales, explaining why they are reported in both Tables 1 and 2. Findings related to the objectives of the narrative review are synthesized narratively in the next section. Results reported that were considered significant were based on the statistical significance determined by the authors of the original study.

\section{Results}

Associations between MW and mood/stressrelated symptoms:

Of the 22 studies included in the review, 13 were conducted using correlational and experimental designs and examining relationships between MW and mood or stress-related measures with questionnaires, thought probes, and experimental tasks in North American, European, and Chinese univer- sities (Appendix 1). Twelve studies tested enrolled undergraduate students, and one study tested volunteers recruited via personal contacts and referrals.

First, an experimental study conducted by Smallwood, Fitzgerald, Miles, \& Phillips (2009) has demonstrated that inducing a negative mood led to a higher level of TUTs and TRIs than the induction of a positive mood. Correlational studies have proposed similar conclusions, showing significant associations between $\mathrm{MW}$ and both negative and positive mood states (Wang, Xu, Zhuang, \& Liu, 2017), and depression symptoms (Giambra \& Traynor, 1978). However, one study conversely obtained a non-significant correlation between MW and depression symptoms (Cundiff \& Gold, 1979). Finally, Marchetti, Koster, \& De Raedt (2012) have shown a significant association between higher $\mathrm{MW}$ and increased accessibility of negative cognitions, but only in participants with moderate and high depression levels. 
In line with these last results, Vinski \& Watter (2013) found that the negative effect of mood on MW was exacerbated in participants evaluated under the high-stress experimental condition compared to the low-stress condition. Likewise, Banks, Tartar, \& Tamayo (2015) have shown that participants under a stress condition had a greater increase in TUTs and state anxiety when compared to those in a control condition. Not only stress under an experimental procedure has been associated with more MW; (1) state anxiety, measured with self-reports, has been shown to significantly predict TUTs and negative TRIs (Banks et al., 2015) and (2) higher levels of stress, also measured with self-reports (Daily Inventory of Stressful Events; DISE) have been associated with increased rates of TUTs (Banks \& Boals, 2017).

Other studies have focused on the content of MW and its associations to mood or stress levels. For instance, Franklin et al. (2013) have shown a relationship between general MW and low mood. They have also looked at the MW levels of interest and usefulness rather than only its presence or absence. MW episodes rated as high-interest and high-usefulness were associated with an increased positive mood compared to MW episodes rated as low-interest or low-usefulness. A few studies investigated MW temporality and whether MW, with a focus on the past, was associated with a negative mood. Smallwood and O'Connor (2011) found that in general, MW was more related to the present than the past or the future; however, lower levels of MW to the present were correlated to more depression symptoms reported on the Beck Depression Inventory (BDI-II). In addition, they reported higher levels of MW related to distant past events following a negative mood induction than a positive mood induction. This increase in past thought was correlated with higher scores on the depression inventory filled in the post-negative mood induction but not pre-induction. Similarly, Poerio et al. (2013) showed that previous feelings of sadness predicted MW related to the past with sad content. In return, MW with sad content pre- dicted a later feeling of sadness. They also demonstrated that previous anxiety predicted MW with anxious content and that MW with anxious content predicted later feeling of anxiety.

Finally, two studies investigated other mechanisms that could account for the association between MW and mood. Carciofo et al. (2016) tested two models with either MW (self-report) or TUTs (thought probes) as the predictor, and negative affect (PANAS scale) as the outcome. When MW was the predictor, endorsement of beliefs about the uncontrollability/danger of thoughts, poor sleep quality, and reduced mindfulness were all significant mediators, and $\mathrm{MW}$ also retained a significant direct effect. As for TUTs, only the beliefs about the uncontrollability of thoughts were a significant mediator and TUTs did not retain a significant direct effect. Lastly, Jonkman, Markus, Franklin, \& van Dalfsen (2017) assessed whether high levels of inattention (ADHD-IA symptoms) affect the association between $\mathrm{MW}$ and negative affect. They reported a higher frequency of retrospective $\mathrm{MW}$ (TUTs and TRIs related to the Sustained Attention to Response Task - SART) in the high ADHD-IA group following a negative mood induction than in the group with low ADHD-IA. Also, after the negative mood induction, the retrospective MW reported during the SART in the group with high ADHD-IA was associated with higher intrusive rumination scores than in the other group. In conclusion, MW and depression symptoms are highly correlated, and this relationship is exacerbated by negative mood, high-stress conditions, and anxiety. Further, content, temporality, and underlying mechanisms also play a role, with $\mathrm{MW}$ with a focus on the past being more strongly correlated to negative mood.

Associations between daydreaming and mood/ stress-related symptoms:

Seven studies were conducted using correlational and experimental designs and investigating the correlations between daydreaming and mood and stress-related symptoms with questionnaires, thought probes, and experimental 
tasks in undergraduate students enrolled in American and British universities (Appendix 2).

More than 40 years ago, Giambra \& Traynor (1978) found that daydreaming frequency, absorption in daydreaming, and frightened reactions to daydreams were all significantly correlated with depression symptoms. These results have been corroborated more recently. Among others, Meyer et al. (2011) reported that the current level of depression symptoms and a past history of depression were significant predictors of a higher level of daydreaming. In addition to depression, the risk for mania also significantly increased daydreaming levels after controlling for the levels of current and former depression (Meyer et al., 2011).

Furthermore, three studies focused on daydreaming with negative content and mood/stress-related variables. First, Cundiff \& Gold (1979) reported that depression symptoms were significantly and positively correlated with fear of failure, guilty daydreams, and boredom daydreams. However, they found no significant association between daydreaming frequency and depression symptoms. Second, Selby et al., (2007) examined violent daydreams associated with depression symptoms and suicidality. They found that a two-way interaction between high levels of violent daydreaming (measured with the Thoughts of Revenge subscale) and high levels of depression symptoms significantly increased the risk of suicidality. Pruzinsky \& Borkovec (1990), have investigated negative daydreaming and stress by comparing individuals with high levels of worry to some with low levels of worry. Their results show that compared to the group with low-level worries, the group with high-level worries reported more negative-valence cognitive intrusions during relaxed wakefulness and focused attention tasks (pre- and post-imagery) and scored significantly higher on the negative daydreaming factor (measured with the Imaginal Processing Inventory).
Finally, a few studies investigated potential mechanisms underlying the association between daydreaming and mood/stress. Cuper \& Lynch (2008) investigated coping styles as mediators between daydreaming and depression symptoms. They reported that fantasy proneness and depression were significantly correlated in participants who feel a lack of control over their lives' direction (locus of control model). These mechanisms were not significantly reported in those who fantasize as a way to divert attention from present experience (avoidant coping), thus neglecting 'real-life' concerns. Moreover, they showed that emotion-focused coping (i.e., "feel overpowered and at the mercy of the situation") significantly mediated the association between daydreaming and depression (Cuper \& Lynch., 2008). Additionally, Carciofo et al. (2016) tested a model with Daydreaming Frequency (DF scale) as the predictor and negative effect as the criterion. They reported that endorsement of beliefs about the uncontrollability of thoughts, poor sleep quality, and reduced mindfulness were all significant mediators, with Daydreaming Frequency retaining a significant direct effect. Thus, daydreaming and depression symptoms are significantly correlated; similarly, the relationship between daydreaming and depression symptoms was exacerbated by negative content and stress, and affected by other mechanisms (e.g., coping styles).

Associations between SCT and mood/stress-related symptoms:

Five studies were conducted using correlational designs and investigating the associations between SCT symptoms and mood/stress-related variables with self-reports in undergraduate students enrolled in American universities (Appendix 3). Two studies (Flannery et al., 2016, 2017) used the same sample of students.

Associations reported between SCT and internalized symptoms were significant and of moderate to strong strength, both for depression (Becker et al., 2019; Flannery et al., 2016; Flannery et al., 2017; Jarrett, Rapport, Rondon, \& Becker, 2017; 
Wood et al., 2017) and anxiety symptoms (Becker et al., 2019; Flannery et al., 2016, 2017; Wood et al., 2017). Becker et al. (2019) also demonstrated that the relationships between SCT and anxiety/ depression symptoms remained significant when controlling for ADHD symptoms. SCT symptoms were also a significant predictor of self-reported emotion ability/regulation, after controlling for depression and anxiety symptoms (Flannery et al., 2016) and ADHD symptoms (Becker et al., 2019).

Two of the identified studies investigated students with high levels of SCT symptoms. First, compared to a control group, a group of students with elevated SCT symptoms reported higher levels of depression, anxiety, and emotion dysregulation (Flannery et al., 2016). Consistent with Flannery et al. (2016), Jarrett et al. (2017) reported higher levels of depression symptoms in the elevated SCT group compared to the control group. However, they also showed higher levels of depression symptoms in the group with combined elevated levels of SCT and ADHD symptoms when com pared to high SCT symptoms only. In conclusion, SCT is significantly correlated to both depression and anxiety symptoms and is a predictor of emotion dysregulation.

\section{Discussion}

The current narrative review sought to comprehensively examine the current literature regarding MW, SCT, and daydreaming - three interrelated constructs (Carciofo et al., 2016; Cundiff \& Gold, 1979; Ostojic, 2018) - and their associations with emotion, stress, anxiety, and depression symptoms in young adults. The included studies varied in terms of design (i.e., experimental, correlational), comparison group, and measures of the variables of interest. Regardless, the existing research provides evidence that all three constructs (MW, daydreaming, SCT) are associated with negative mood and emotions, and stress/ anxiety symptoms in the young adult population (Carciofo et al., 2017; Becker et al., 2018; Smallwood et al., 2008). This review also provides some evidence and discussion related to the direction- ality of these associations, mechanisms involved, and propositions for future research.

As mentioned earlier, this review's theme is especially relevant for our studied population - young adults - for a host of reasons. For one, there is evidence suggesting a higher prevalence of our three constructs of interest (MW, daydreaming, SCT) in samples of young adults in contrast with children and older adults (Maillet et al., 2018; Giambra, 2000; Flannery et al., 2016; Jarrett et al., 2014; Wood et al., 2017). While the focus of the review on young adulthood restricts generalization to other age groups, it provides a focused review to better understand the nature of these associations during that stage of life. Young adulthood - also referred as emerging adulthood, a distinctive developmental period between adolescence and full-blown adulthood (Tanner \& Arnett, 2016; Arnett, 2000 - is a unique period in regards to psychological functioning given that it is fraught with (1) increased vulnerability to negative life events (Braboy Jackson \& Finney, 2002) and (2) important changes in terms of family and friends circles, and loss of familiar surroundings (Beck and Young, 1978). Further, high levels of MW, daydreaming, SCT, stress, and negative mood have been shown to relate with multiple domains of their lives, such as social impairment (Flannery et al., 2016), academic outcomes (Mooneyham \& Schooler, 2013), and lower life satisfaction (Mar, Mason, \& Litvack, 2012).

\section{Correlational and content-based approaches:}

The documented studies agree that increased levels of MW are correlated with higher levels of depression, anxiety, negative emotions, and stress. These factors correlate regardless of whether MW was measured with a diverse range of questionnaires (Wang \& Zhang, 2017; Poerio et al., 2013) or with thought probes, including TUTs and TRIs (Carciofo et al., 2016; Marchetti et al., 2012; Franklin et al., 2013; Smallwood et al., 2009). This resonates with the findings of a study conducted by Seli, Risko, \& Smilek (2016), in which they reported correspondence between trait- and state-level scales of MW. These associations between MW and mood/ 
stress-related symptoms were replicated across correlational studies analyzing daydreaming (Giambra \& Traynor, 1978; Pruzinsky \& Borkovec, 1990) and SCT symptoms (Becker et al., 2018; Flannery et al., 2017; Wood et al., 2017; Becker et al., 2019; Jarrett et al., 2017; Flannery et al., 2016), suggesting that the findings above are generalizable to the latter two constructs.

Some correlational studies have looked at the content or temporality of MW. Results have demonstrated that negative valence intrusions (Pruzinsky \& Borkovec, 1990) and MW with anxious content (Poerio et al., 2013) were related to higher levels of worry. MW with sad content (Poerio et al., 2013), MW more related to the past and less to the present (Smallwood \& O'Connor, 2011), daydreaming with violent content (Selby et al., 2007), and daydreaming with content related to boredom, guilt, and fear of failure (Cundiff \& Gold, 1979) were associated to more negative mood or depression symptoms. Overall, it is possible to hypothesize that the MW's specific negative or past-related content could exacerbate the already existing associations between higher levels of MW and mood/stress levels.

\section{Evidence from longitudinal and experimental} approaches:

While this review suggests associations between MW, daydreaming, SCT, and psychological functioning (emotions, mood, stress, depression, and anxiety), directionality remains unclear since many studies have used cross-sectional correlational designs. These study designs do not allow us to make any inferences regarding these relationships' causality and directionality. To our best knowledge, only Poerio et al. (2013) conducted a longitudinal correlational study, lending support to the idea that the association between MW with negative content and negative feelings could be bidirectional. They also showed that previous negative feelings were predicting higher levels of general MW, whereas MW itself was not predicting later negative feelings. Rather, it was the specific content of MW that was correlated to later negative feelings (Poerio et al., 2013). These results suggest that the feelings could increase general MW rather than the opposite. However, they retrospectively investigated feelings immediately after assessing MW (asking about feelings experienced 15 minutes pre-testing), which could have introduced recall bias, inflated results, and consequently limit the extent of the conclusions regarding directionality. Nonetheless, some experimental studies had results in line with Poerio et al.'s (2013) study, showing that inducing high stress (Vinski \& Watter, 2013) and negative mood conditions (Smallwood et al., 2009; Jonkman et al., 2017; Smallwood \& O'Connor, 2011) resulted in higher levels of $M W$ tested with both probes (Vinski \& Watter, 2013; Jonkman et al., 2017; Smallwood \& O'Connor, 2011) and questionnaires (Vinski \& Watter, 2013; Smallwood et al., 2009; Jonkman et al., 2017; Smallwood \& O'Connor, 2011; Poerio et al., 2013). These results also suggest that high mood and stress would lead to more MW than the opposite. However, no known studies have experimentally induced MW (e.g., an experimental condition where participants are invited to think about "whatever comes to mind"; Arche \& Craske, 2006) and subsequently measure mood and stress levels. This study would be necessary to determine if $\mathrm{MW}$ induction could also lead to higher levels of low mood and stress.

\section{Potential mechanisms involved and clinical implications:}

Some of the studies included in this review have investigated mechanisms operating within these associations. Tested mechanisms include psychological, physical, familial, and biological factors. For instance, reduced levels of mindfulness (Carciofo et al., 2016; Mooneyham \& Schooler, 2013; Xu, Purdon, Seli, \& Smilek, 2017) and higher levels of ruminations (Shrimpton, McGann, \& Riby, 2017) have been shown as mechanisms. These mechanisms suggest that the ability to stay in the present moment or to show metacognitive regulation could help to redirect the attention towards the task at hand (Mrazek, Smallwood, \& Schooler, 2012), and 
thus, reduce negative affect. The endorsement of beliefs about the uncontrollability of thoughts (Carciofo et al., 2016) and emotion-focused coping (Cuper \& Lynch., 2008) have also been shown as significant mediators for daydreaming/ MW-negative mood. This concept proposes that a cognitive focus and lack of control on negative emotions appears to contribute to the maintenance of this association. Neuroticism is a personality dimension involving anxiety, moodiness, worry, and envy. Neuroticism is another potential mediator of the relationship between MW, SCT, daydreaming, and mood/stress-related symptoms, as it has been reported that individuals who score high on this trait are prone to more frequent MW (Baer, Smith, Hopkins, Krietemeyer, \& Toney, 2006; Giluk, 2009) and lower levels of well-being (Diener, Suh, Lucas, \& Smith, 1999). More distal mechanisms have also been identified as potentially underlying the associations between $\mathrm{MW}$ and negative affect, including poor sleep quality (Carciofo et al., 2016) and high levels of inattentive symptoms of ADHD (Jonkman et al., 2017). Additionally, a recent study on familial factors has shown that a negative emotional climate in the family strengthened the relation between SCT and depression symptomatology in young adults (Fredrick et al., 2019)

Biological mechanisms can also be proposed For instance, a study on the relationship between self-generated thoughts and stress reported that social thoughts with a focus on the future were associated with a decrease in overall cortisol levels, while negatively toned emotional thoughts were associated with an increase in overall cortisol levels (Engert, Smallwood, \& Singer, 2014). Significant brain activity has also been reported in several key areas (i.e., prefrontal cortex, posterior cingulate cortex, and the inferior parietal lobule bilaterally) during MW (Mason, Brown, Mar, \& Smallwood, 2013). Given that links have been established between MW and negative affect, these brain regions could be neurobiological substrates of $\mathrm{MW} / \mathrm{SCT} /$ daydreaming-mood/stress associ- ations; however, to date, these implications have only been proposed theoretically and not yet studied empirically.

The clinical implications of these results are far-reaching, insofar as they lend support to the need for assessment and intervention that (1) identifies vulnerable populations and (2) tailors effective coping strategies to facilitate dealing with these thoughts and feelings when they arise. Namely, clinicians could benefit from being aware of these associations when evaluating and providing psychological support to young adults. For instance, excessive $\mathrm{MW}$ is increasingly being used to assess ADHD (Bozhilova, Michelini, Kuntsi, \& Asherson, 2018; Mowlem, Agnew-Blais, Pingault, $\&$ Asherson, 2019). Similar efforts should be made to replicate this work across studies investigating SCT, since (1) it also has been hypothesized to reflect pathological MW (Barkley, 2014) and (2) the associations between SCT and depression symptoms (Jarrett et al., 2017) and between MW and negative mood (Jonkman et al., 2017) seems to increase when ADHD is co-occurring. Furthermore, taking into account temporality and content of MW, daydreaming, and SCT symptoms - as well as potential mechanisms previously described (e.g., mindfulness, rumination, sleep) - could allow for more tailored assessment and evidence-based therapies that address these mechanisms, such as cognitive-behavioural and mindfulness-based approaches.

Limitations and future studies:

There were several methodological strengths and limitations in the included studies. One limitation is the relative lack of representative samples; while they centred around young adults, studies in this review overwhelmingly focused on university students, limiting generalizability. Out of the 22 studies included, 21 reviews tested university students. The unique nature of the university experience may exacerbate the prevalence of these associations in young adults. Future studies should aim to examine the levels of SCT, MW, and daydreaming 
symptoms (and their interactions with mood disorder symptoms, stress, and negative emotions) by comparing samples of university students to samples from the general population. Additionally, race differences were not studied, and the samples were composed mainly of females. Both female and male undergraduate students were found to be affected by MW, SCT, and daydreaming; however, occurrence levels and how they manifest themselves likely differ between sexes (Raymond et al., 2019). Therefore, race and sex should be considered in future studies on this topic.

Future studies are also warranted to address the lack of longitudinal and experimental studies looking at SCT/MW/daydreaming in relation to mood-stress related symptoms. For instance, future research should compare rates of SCT, MW and daydreaming at the beginning and end of every subsequent year of a university degree as well as its longitudinal associations with mood/ stress-related symptoms. This comparison would allow us to further our efforts to better understand these associations and their directionality while controlling for environmental stress factors. Moreover, experimental designs with the induction of MW, stress, and mood are needed to better establish causality relationships and understand underlying mechanisms. These experiments should also be repeated with daydreaming and SCT, given that there is no known current experimental research investigating mood/stress variables in relation to daydreaming/SCT. Experimental and cognitive psychologists may also find it worthwhile to collaborate with neuroscientists on future studies seeking to capture MW and brain activity in experimental settings. More specifically, we propose to conduct future studies that assess the neural processes underlying MW/daydreaming/SCT and mood/stress-related associations in pre- and post-mood induction and stress conditions. These studies are recommended to solidify inferences made in the present review.
An additional challenge that presents itself in studying the nature and strength of these associations is the lack of clarity in conceptual and definitional distinctions between various $\mathrm{MW}$ forms. For instance, while the included studies suggested little difference in outcomes between probes used, none of them differentiated between intentional and non-intentional MW, which is of crucial importance given that research has shown that these two types of MW can be independent predictors of variables of theoretical interest (Seli, Risko, Smilek, \& Schacter, 2016). Indeed, unintentional MW has been uniquely associated with ADHD (Seli, Smallwood, Cheyne, \& Smilek, 2015) and OCD (Seli, Risko, Purdon, \& Smilek, 2017), while research did not replicate these observations in cases of intentional MW. Therefore, such distinctions are needed to confirm and refine our conclusions.

Moreover, there is still a lack of clarity regarding the definition of MW (see Christoff, Irving, Fox, Spreng, \& Andrews-Hanna, 2016; Irving, 2016; Seli et al., 2018 for different perspectives). To circumvent this issue, Seli et al., (2018) propose a family-resemblance approach wherein $\mathrm{MW}$ is a natural category with graded membership. Additionally/alternatively, researchers could ask a variety of people (e.g., experts, laypeople) to describe exemplars of MW from which they could assess overlapping features (Seli et al., 2018). Consequently, future studies - such as qualitative studies - should aim to clearly define $\mathrm{MW}$, differences and similarities between $\mathrm{MW}$ and daydreaming, other dimensions of the construct, and their unique relationships with mood disorder symptoms, negative emotions, and stress.

Finally, the methodological limitations of this review should be considered. First, we limited our search to two databases and used a small set of key terms, which means we may have missed some relevant studies. Secondly, the review only included 22 articles, which limits the confidence with which results are generalizable to the general population of young adults. Thirdly, all the results document- 
ed were from published articles, which may also partially reflect publication bias, resulting in an overestimation of the strength of the associations reported.

\section{Conclusions}

This narrative review highlights the current state of knowledge, suggesting that high levels of MW, daydreaming, or SCT symptoms in young adults are associated with greater negative mood/ stress-related symptoms. This review is important because the links between MW, daydreaming, and SCT should be understood before psychological support is provided to the most affected populations (young adults), especially because of comorbidity risks and the uniqueness that characterizes emerging adulthood. However, the available literature documenting the directionality of these associations and mechanisms behind these relationships remains incomplete. Furthermore, studies in the field of research have yet to consider other important variables that might moderate these associations (e.g., sex, race, university and non-university students). Additional research that combines diverse samples, designs (i.e., longitudinal and experimental) and expertise (i.e., cognitive, clinical, and neurobiological) is thus needed to bring to light the directionality and nature of these associations. This research is specifically important given the significant ratio of young adults experiencing high levels of SCT (Flannery et al., 2016; Leopold et al., 2016) but also significant levels of anxiety or mood disorders (25\% to $40 \%$ in industrialized countries; Aalto-Setälä, Marttunen, Tuulio-Henriksson, Poikolainen, \& Lönnqvist, 2001; Kringlen, Torgersen, \& Cramer, 2001). A better understanding of these associations key underlying mechanisms could help orientate treatment research and clinical work targeting these factors, with the ultimate goal of yielding better outcomes and well-being in young adults.

\section{Acknowledgments}

The authors thank Sarah Shaughnessy, librarian, for her help with developing and adapting the search strategy. This study was funded by the Apprentis Chercheurs Research Award, an endowment held by the Faculty Saint-Jean's research office and granted to Gladys Sina by the University of Alberta's Faculty Saint-Jean.

\section{Declaration of Interests}

Both authors have no conflict of interest to declare. 


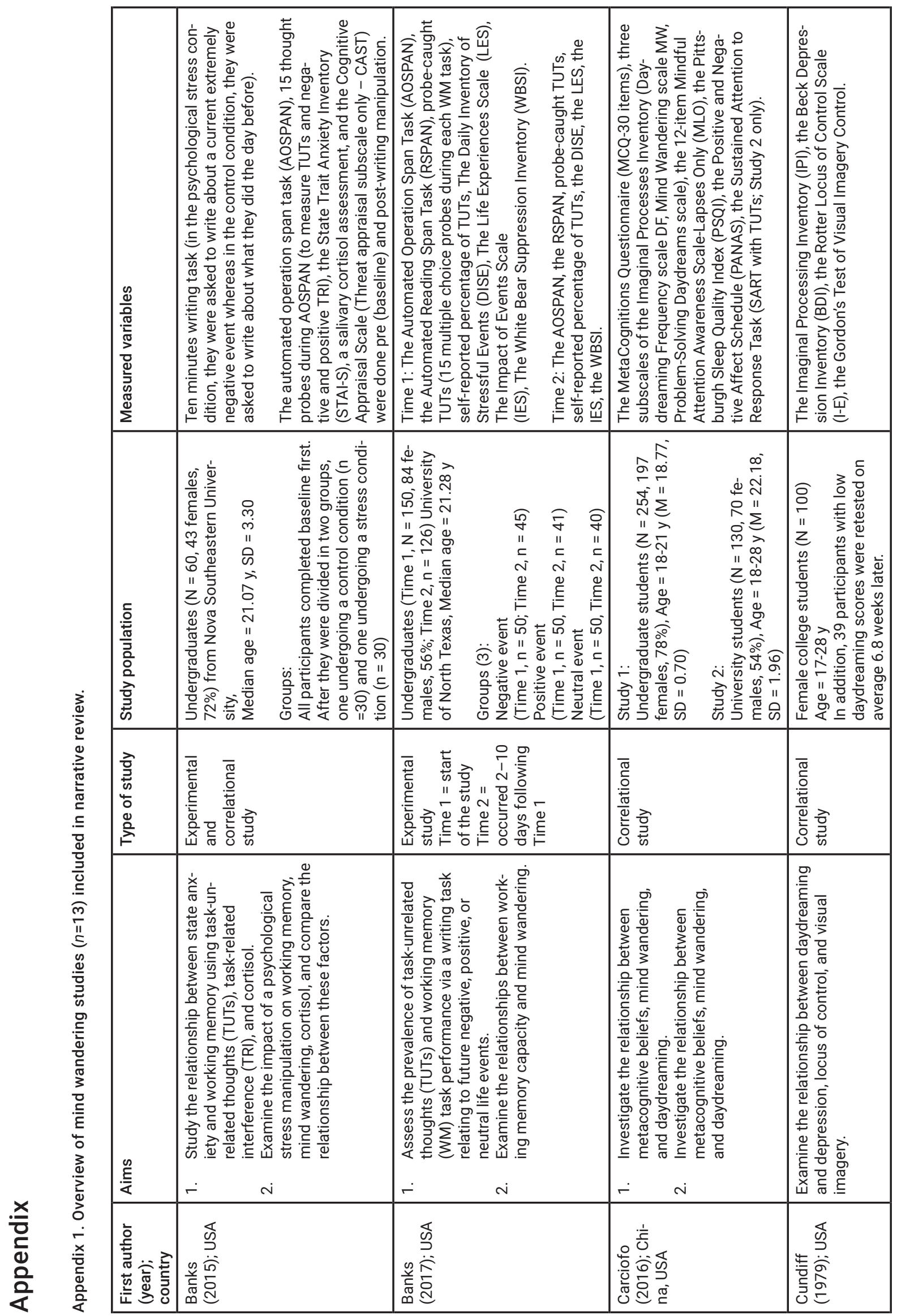




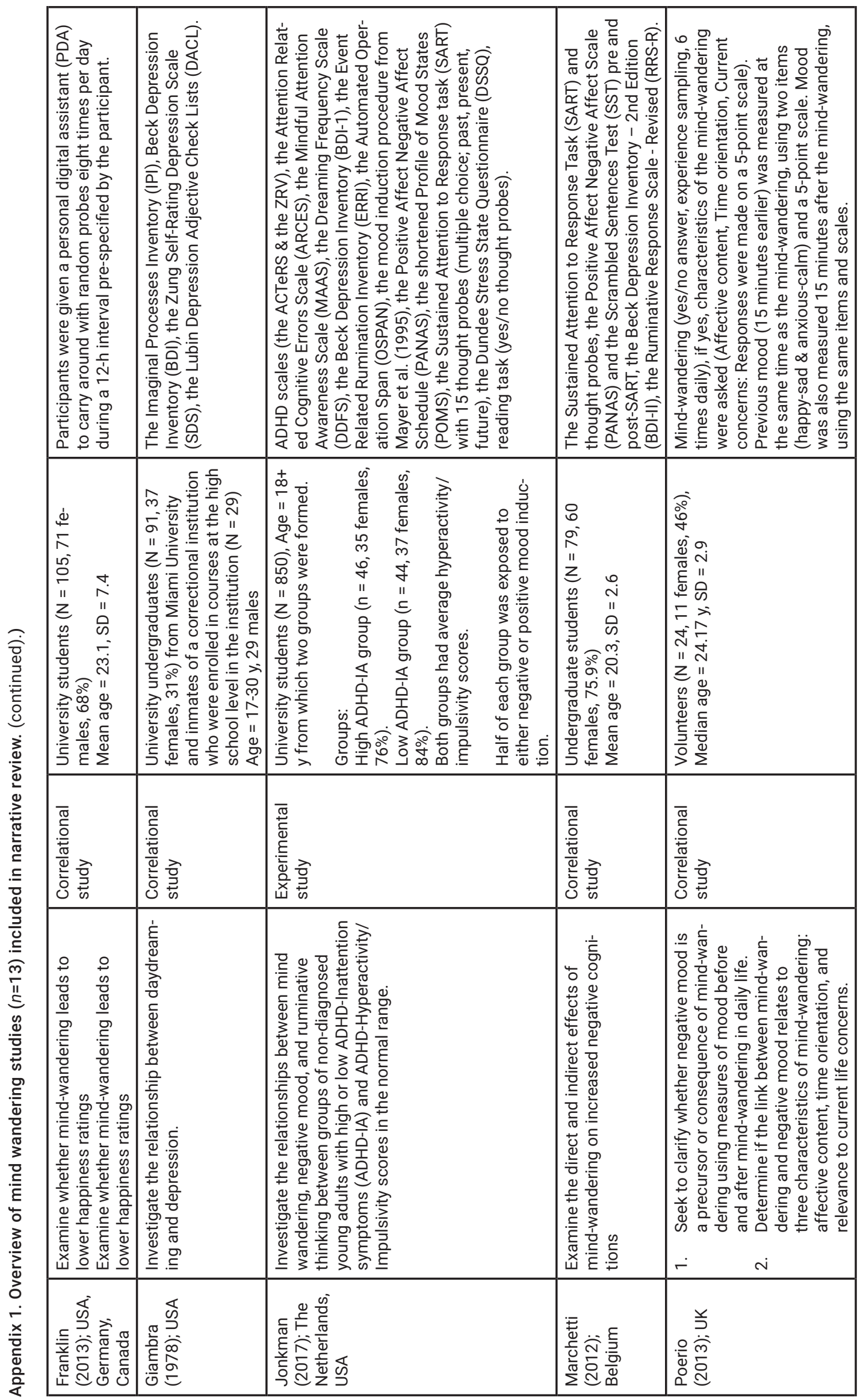




\begin{tabular}{|c|c|c|c|c|}
\hline 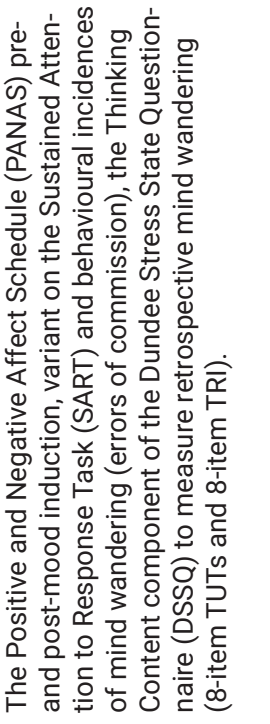 & 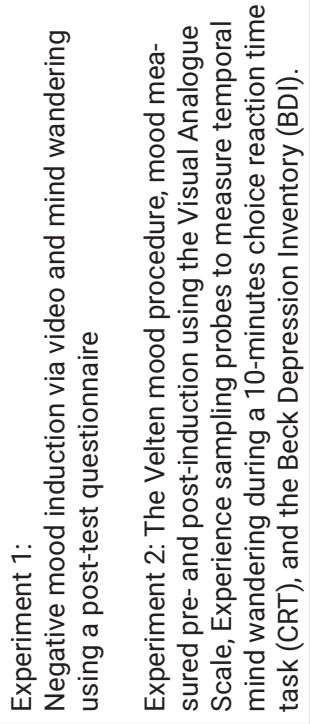 & 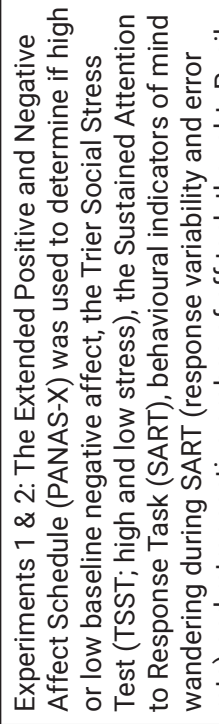 & & 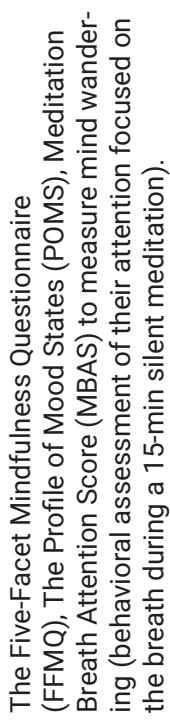 \\
\hline 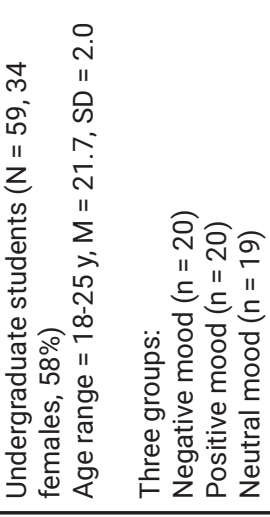 & 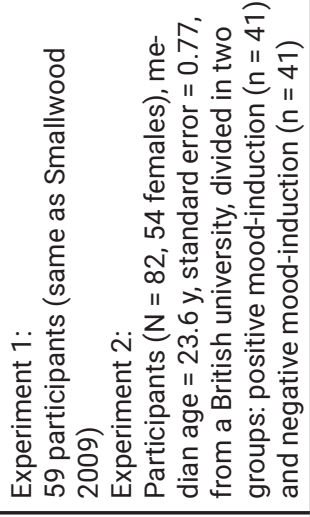 & 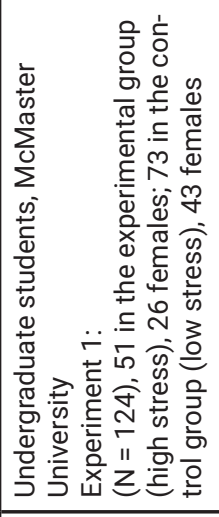 & 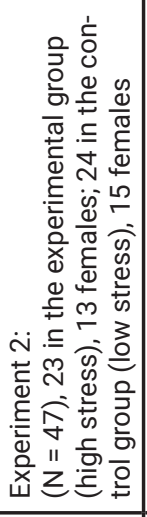 & 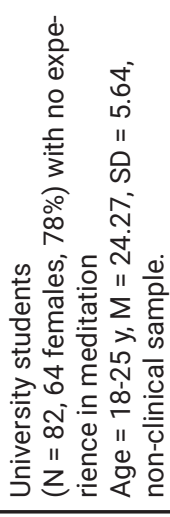 \\
\hline 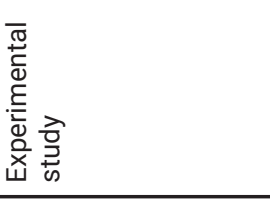 & 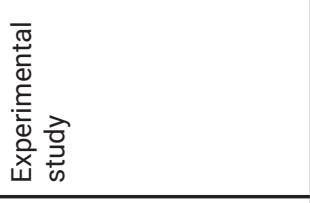 & 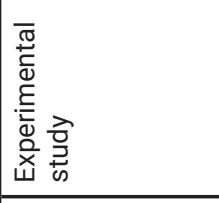 & & 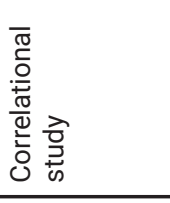 \\
\hline 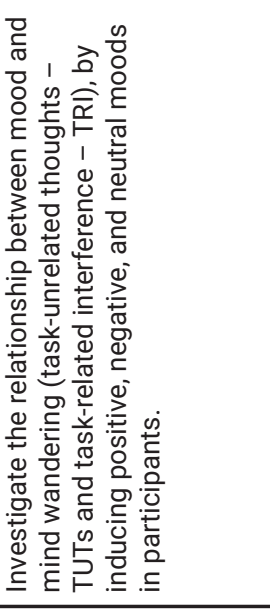 & 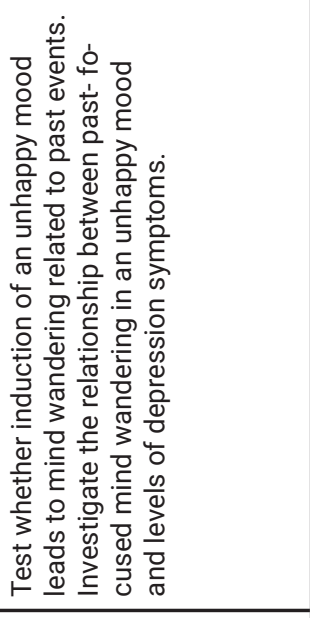 & 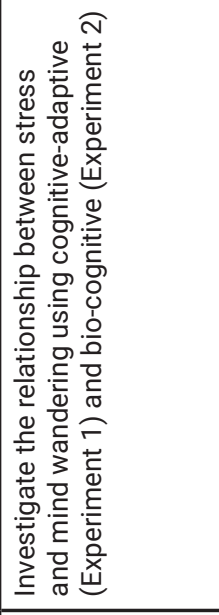 & & 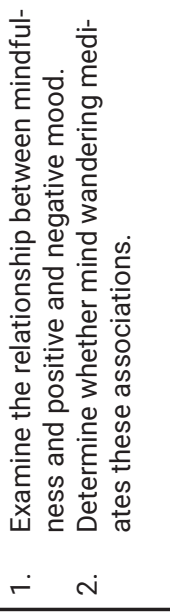 \\
\hline 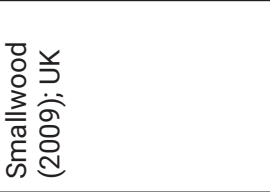 & 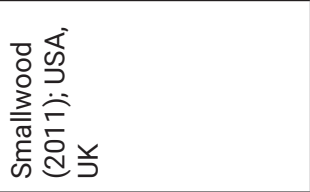 & 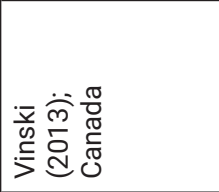 & & 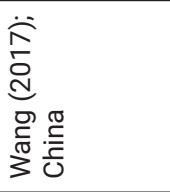 \\
\hline
\end{tabular}




\begin{tabular}{|c|c|c|c|c|c|c|}
\hline 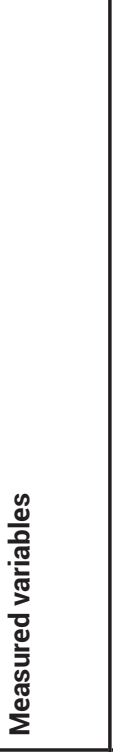 & 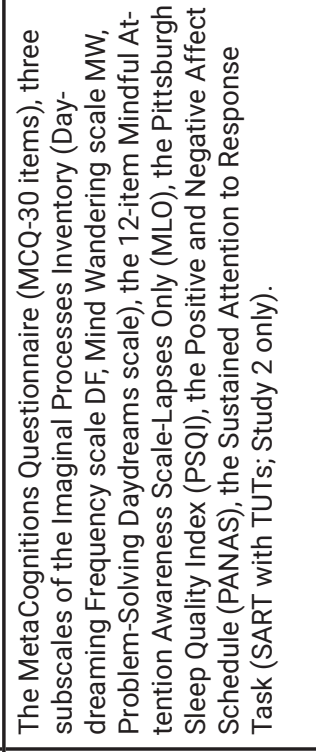 & 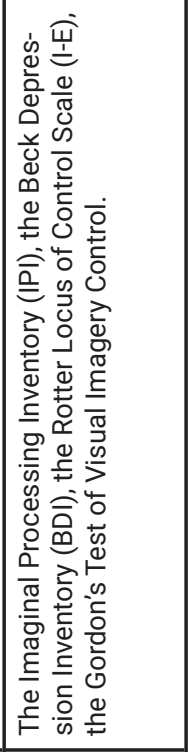 & 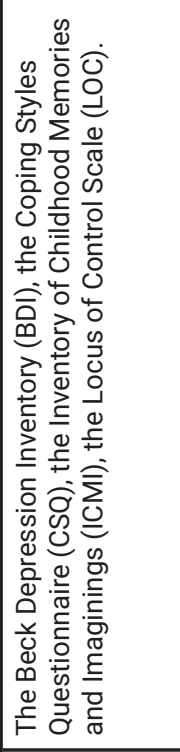 & 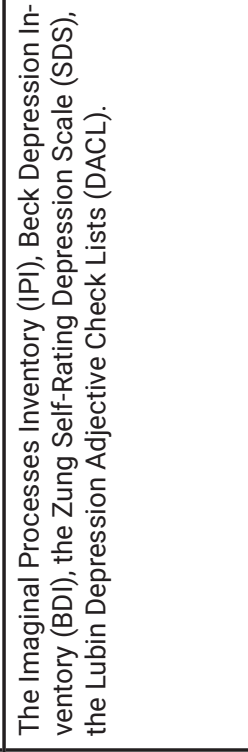 & 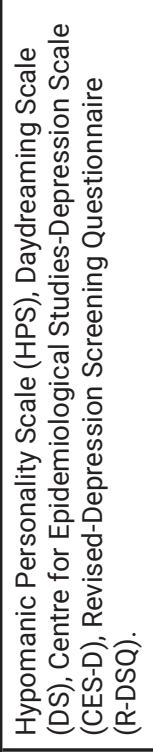 & \\
\hline $\begin{array}{l}\frac{}{0} \\
\frac{\pi}{0} \\
\frac{0}{3} \\
\frac{0}{2} \\
\frac{0}{2} \\
\frac{0}{3} \\
\text { c }\end{array}$ & 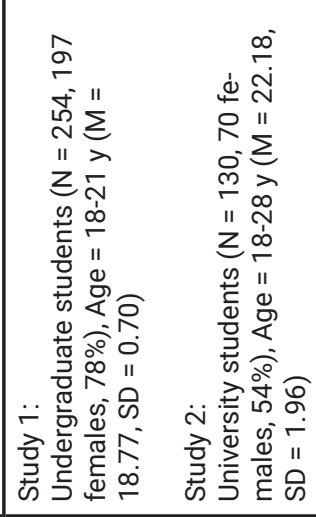 & 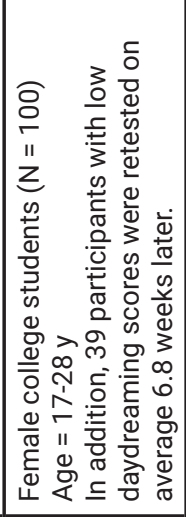 & 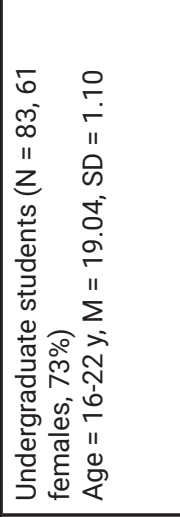 & 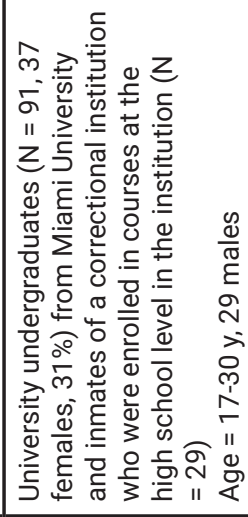 & 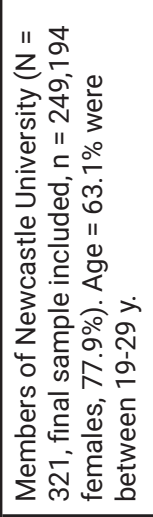 & 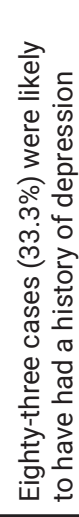 \\
\hline 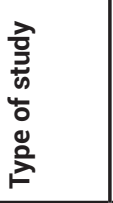 & 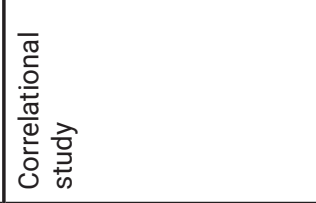 & 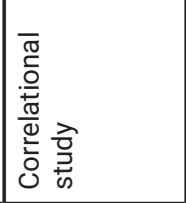 & 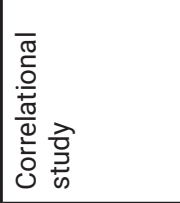 & 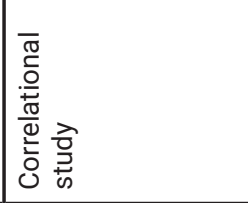 & 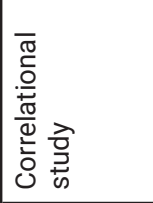 & \\
\hline 音 & 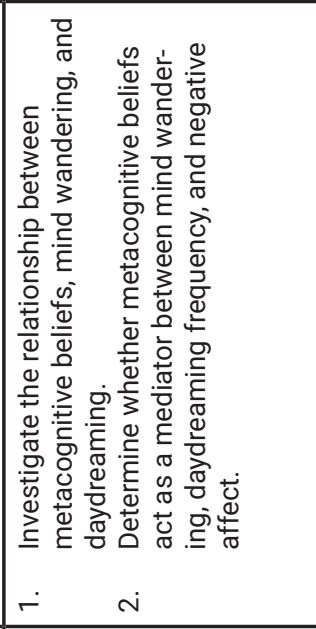 & 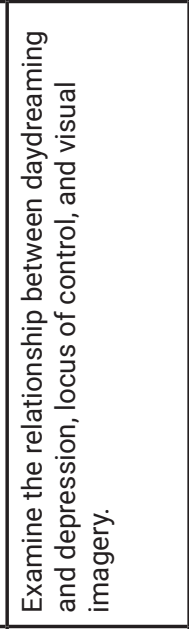 & 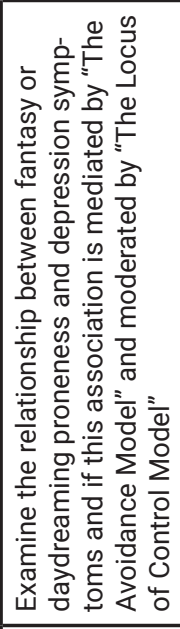 & 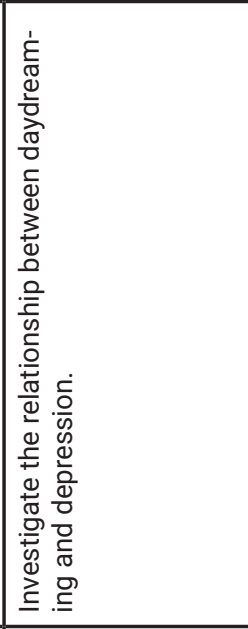 & 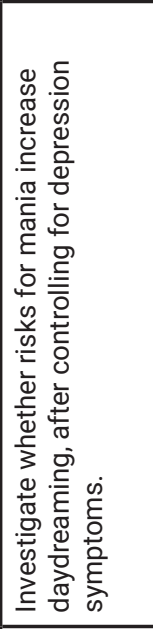 & \\
\hline 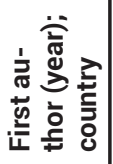 & 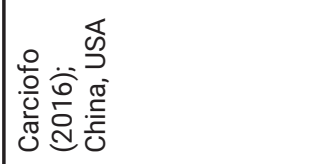 & 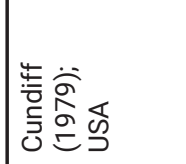 & 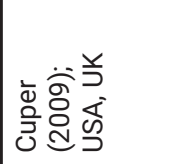 & 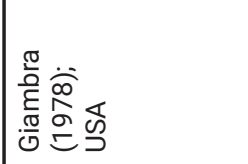 & 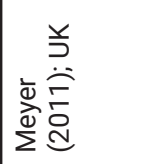 & \\
\hline
\end{tabular}




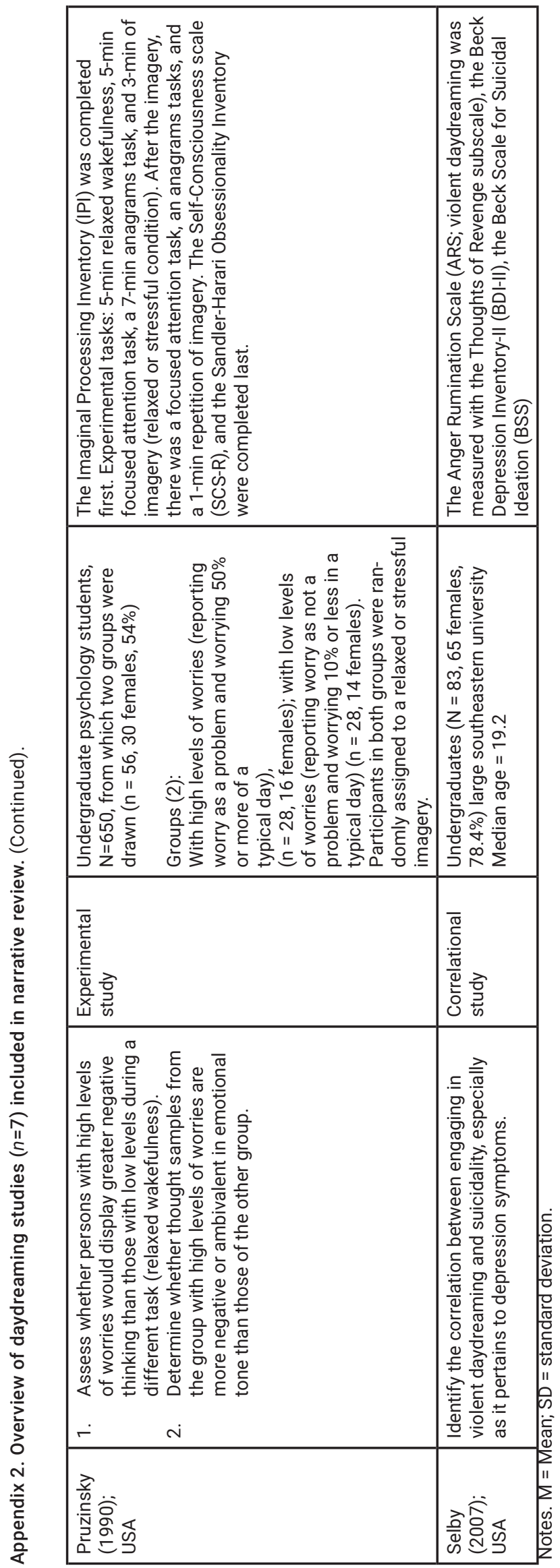




\begin{tabular}{|c|c|c|c|c|c|}
\hline & 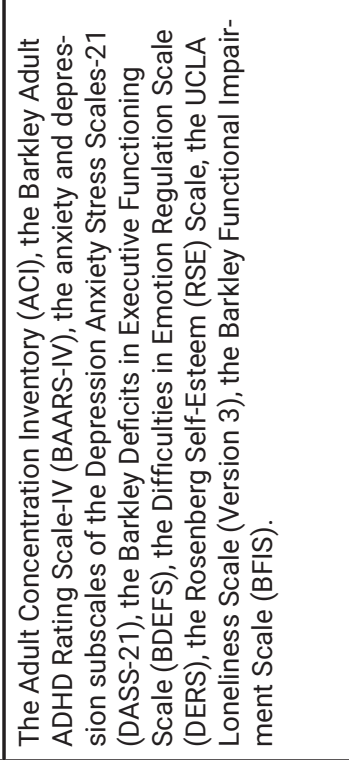 & 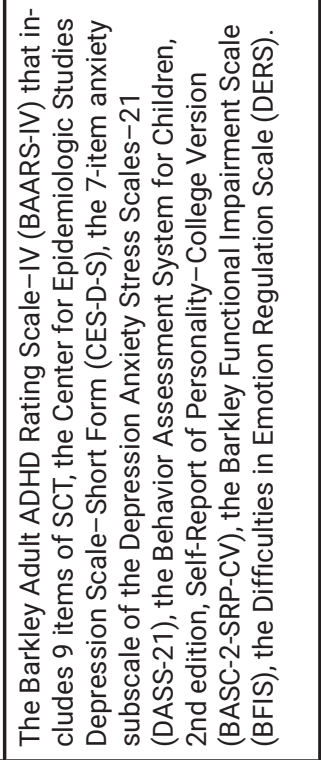 & 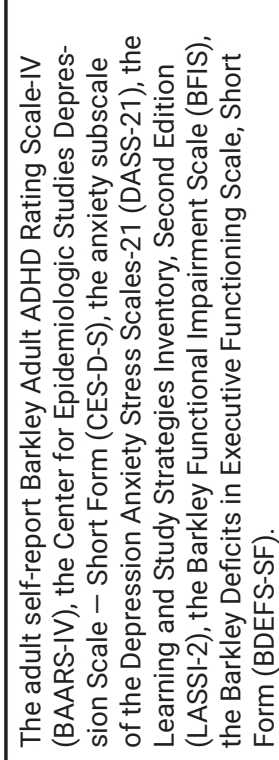 & \multicolumn{2}{|c|}{ 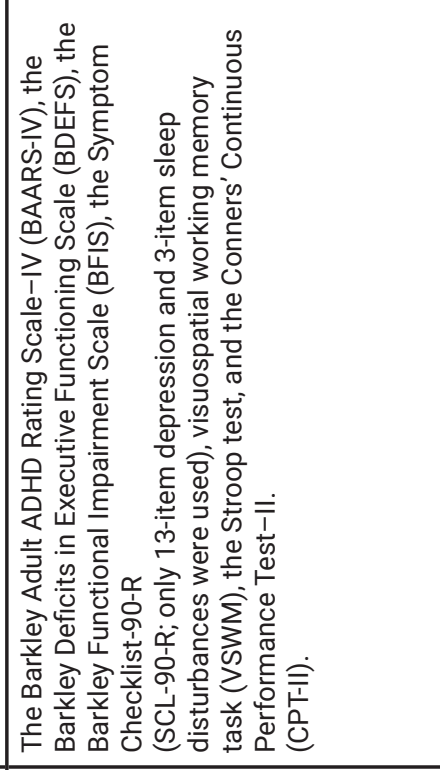 } \\
\hline & 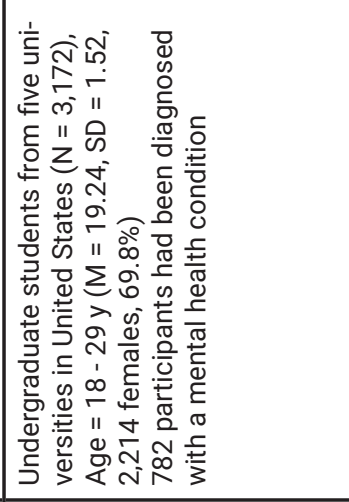 & 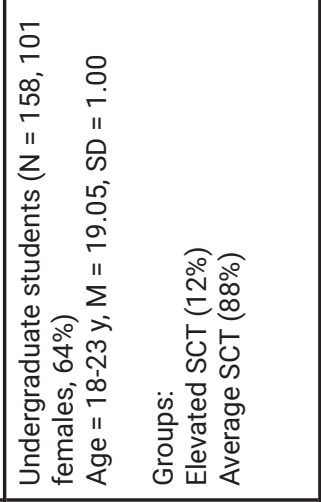 & 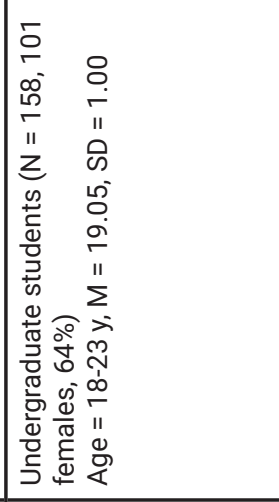 & 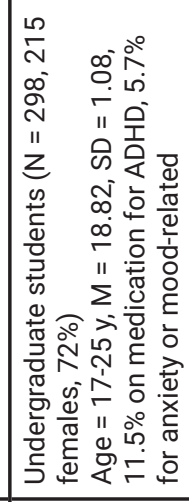 & 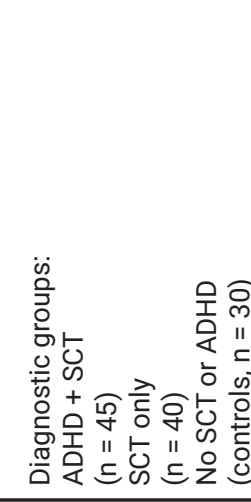 \\
\hline & 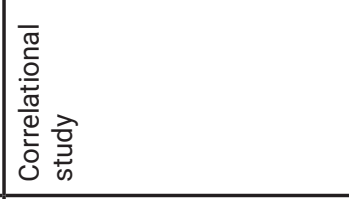 & 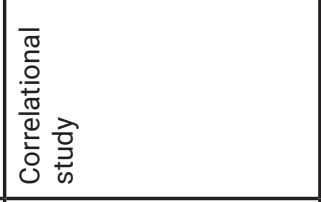 & 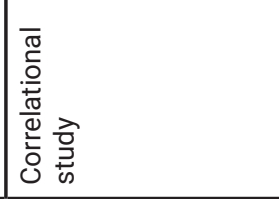 & 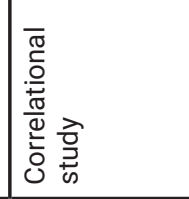 & \\
\hline$\stackrel{\infty}{\overbrace{}^{\frac{E}{4}}}$ & 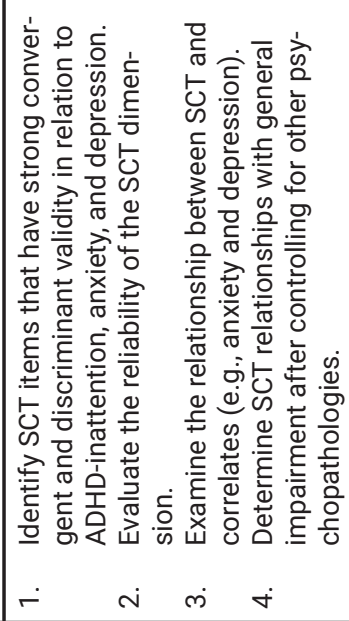 & 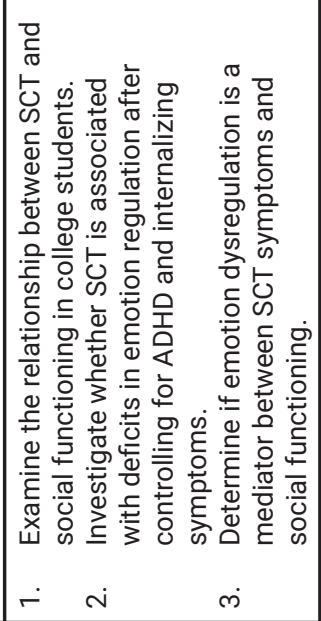 & 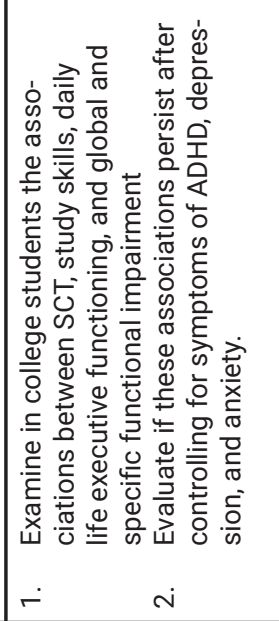 & 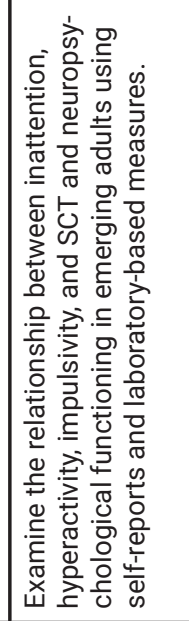 & \\
\hline 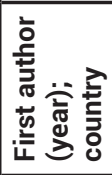 & 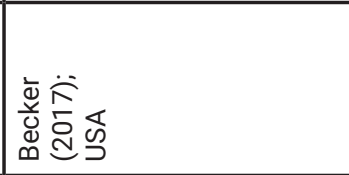 & 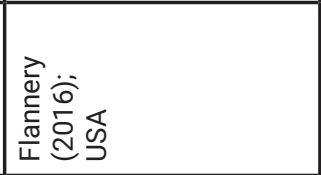 & 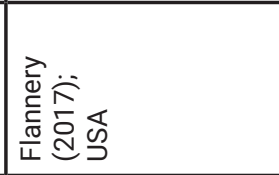 & 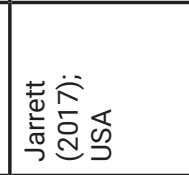 & \\
\hline
\end{tabular}




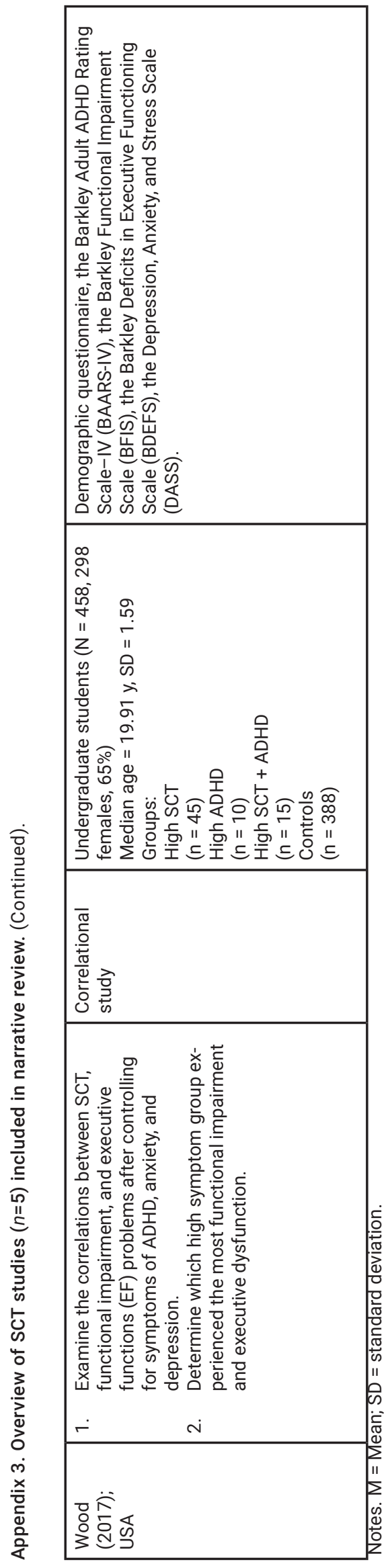




\section{Works Cited}

1. Aalto-Setälä, T., Maruunen, M., Tuulio-Henriksson, A., Poikolainen, K., \& Lönnquist, J., (2001). Onemonth prevalence of depression and other DSM-IV disorders among young adults. Psychological Medicine, 31, 791-801. https://doi.org/10.1176/appi.ajp.159.7.1235

2. Arch, J. J., \& Craske, M. G. (2006). Mechanisms of mindfulness: Emotion regulation following a focused breathing induction. Behavior Research and Therapy, 44, 1849-1858. https://doi.org/10.1016/j. brat.2005.12.007

3. Arnett, J. J. (2000). Emerging adulthood. American Psychologist, 55(5), 469-480. https://doi. org/10.1037/0003-066X.55.5.469

4. Baer, R. A., Smith, G. T., Hopkins, J., Krietemeyer, J., \& Toney, L. (2006). Using self-report assessment methods to explore facets of mindfulness. Assessment, 13(1), 27-45. https://doi. org/10.1177/1073191105283504

5. Baird, B., Smallwood, J., \& Schooler, J. W. (2011). Back to the future: autobiographical planning and the functionality of mind-wandering. Consciousness and Cognition, 20, 1604-1611. https://doi. org/10.1016/j.concog.2011.08.007

6. Banks, J. B., \& Boals, A. (2017). Understanding the role of mind wandering in stress-related working memory impairments. Cognition \& Emotion, 31(5), 1023-1030. https://doi.org/10.1080/02699931.201 6.1179174

7. Banks, J. B., Tartar, J. L., \& Tamayo, B. A. (2015). Examining factors involved in stress-related working memory impairments: Independent or conditional effects?. Emotion, 15(6), 827-836. https://doi. org/10.1037/emo0000096

8. Barkley, R. A. (2012). Distinguishing sluggish cognitive tempo from attention-deficit/hyperactivity disorder in adults. Journal of Abnormal Psychology, 121, 978-990. https://doi.org/10.1037/a0023961

9. Barkley, R. A. (2014). Sluggish cognitive tempo (concentration deficit disorder?): Current status, future directions, and a plea to change the name. Journal of Abnormal Child Psychology, 42(1), 117-125. https://doi.org/10.1007/s10802-013-9824-y

10. Beck, A.T., Young, J.E. (1978). College Blues. Psychol. Today pp. 83-92. Benton, S.A., Robertson, J.M., Tseng, W.C., Newton, F.B., Benton, S.L. (2003). Changes in counseling center client problems across 13 years. Professional Psychology: Research and Practice, 34: 66-72. https://doi.org/10.1037/07357028.34.1.66

11. Beck, A. T, Hollon, S. D., Young, J. E., Bedrosian, R. C., \& Budenz, D. (1985). Treatment of depression with cognitive therapy and amitriptyline. Archives of General Psychiatry, (2), 142. https://doi. org/10.1001/archpsyc.1985.01790250036005

12. Becker, S. P., \& Langberg, J. M. (2013). Sluggish cognitive tempo among young adolescents with ADHD. Journal of Attention Disorders, 17(8), 681-689. https://doi.org/10.1177/1087054711435411

13. Becker, S. P., Burns, G. L., Garner, A. A., Jarrett, M. A., Luebbe, A. M., Epstein, J. N., \& Willcutt, E. G. (2018). Sluggish cognitive tempo in adults: Psychometric validation of the adult concentration inventory. Psychological Assessment, 30(3), 296-310. https://doi.org/10.1037/pas0000476

14. Becker, S. P., Garner, A. A., Tamm, L., Antonini, T. N., \& Epstein, J. N. (2019). Honing in on the social difficulties associated with sluggish cognitive tempo in children: Withdrawal, peer ignoring, and low engagement. Journal of Clinical Child \& Adolescent Psychology, 48(2), 228-237. https://doi.org/10.10 80/15374416.2017.1286595

15. Becker, S., Luebbe, A., Fite, P., Stoppelbein, L., \& Greening, L. (2014). Sluggish cognitive tempo in psychiatrically hospitalized children: Factor structure and relations to internalizing symptoms, social problems, and observed behavioral dysregulation. Journal of Abnormal Child Psychology, 42(1), 49- 
62. https://doi.org/10.1007/s10802-013-9719-y

16. Becker, S., Marshall, S., \& McBurnett, K. (2014). Sluggish cognitive tempo in abnormal child psychology: An historical overview and introduction to the special section. Journal of Abnormal Child Psychology, 42(1), 1-6. https://doi.org/10.1007/s10802-013-9825-x

17. Bozhilova, N. S., Michelini, G., Kuntsi, J., \& Asherson, P. (2018). Mind wandering perspective on attention-deficit/hyperactivity disorder. Neuroscience and Biobehavioral Reviews, 92, 464-476. https:// doi.org/10.1016/j.neubiorev.2018.07.010

18. Carciofo, R., Song, N., Du, F., Wang, M. M., \& Zhang, K. (2017). Metacognitive beliefs mediate the relationship between mind wandering and negative affect. Personality and Individual Differences, 107, 78-87. https://doi.org/10.1016/j.paid.2016.11.033

19. Carciofo, R., Yang, J., Song, N., Du, F., \& Zhang, K. (2016). Psychometric evaluation of Chinese-language 44-item and 10-item big five personality inventories, including correlations with chronotype, mindfulness and mind wandering. PLoS One, 11(2), e0149963. https://doi.org/10.1371/journal. pone.0149963

20. Carlson, C., Mann, M. (2002). Sluggish cognitive tempo predicts a different pattern of impairment in the attention deficit hyperactivity disorder, predominantly inattentive type. Journal of Clinical Child \& Adolescent Psychology, 31, 123-129. https://doi.org/10.1207/157344202753441738

21. Carruthers, P. (2015). The centered mind. Corby: Oxford University Press.

22. Christoff, K., Irving, Z. C., Fox, K. C. R., Spreng, R. N., \& Andrews-Hanna, J. R. (2016). Mind-wandering as spontaneous thought: A dynamic framework. Nature Reviews. Neuroscience, 17(11), 718-731. https://doi.org/10.1038/nrn.2016.113

23. Cundiff, G., \& Gold, S. R. (1979). Daydreaming: A measurable concept. Perceptual \& Motor Skills, 49(2), 347-353. https://doi.org/10.2466/pms.1979.49.2.347

24. Cuper, P. F., \& Lynch, T. R. (2008 -2009). When is fantasy proneness associated with distress? an examination of two models. Imagination, Cognition and Personality, 28(3), 251-268. https://doi. org/10.2190/IC.28.3.d

25. Diener, E., Suh, E. M., Lucas, R. E., \& Smith, H. L. (1999). Subjective well-being: Three decades of progress. Psychological Bulletin, 125(2), 276-302. https://doi.org/10.1037//0033-2909.125.2.276

26. Dunn, L. W., Corn, A. L., \& Morelock, M. J. (2004). The relationship between scores on the ICMIC and selected talent domains: An investigation with gifted adolescents. Gifted Child Quarterly, 48, 133142. https://doi.org/10.1177/001698620404800206

27. Engert, V., Smallwood, J., \& Singer, T. (2014). Mind your thoughts: Associations between self-generated thoughts and stress-induced and baseline levels of cortisol and alpha-amylase. Biological Psychology, 103, 283-291. https://doi.org/10.1016/j.biopsycho.2014.10.004

28. Flannery, A. J., Becker, S. P., \& Luebbe, A. M. (2016). Does emotion dysregulation mediate the association between sluggish cognitive tempo and college students' social impairment?. Journal of Attention Disorders, 20(9), 802-812. https://doi.org/10.1177/1087054714527794

29. Flannery, A. J., Luebbe, A. M., \& Becker, S. P. (2017). Sluggish cognitive tempo is associated with poorer study skills, more executive functioning deficits, and greater impairment in college students. Journal of Clinical Psychology, 73(9), 1091-1113. https://doi.org/10.1002/jclp.22406

30. Fox, K. C. R., Andrews-Hanna, J. R., \& Christoff, K. (2016). The neurobiology of self-generated thought from cells to systems: Integrating evidence from lesion studies, human intracranial electrophysiology, neurochemistry, and neuroendocrinology. Neuroscience, 335, 134-150. https://doi.org/10.1016/j. neuroscience.2016.08.020

31. Franklin, M. S., Mrazek, M. D., Anderson, C. L., Smallwood, J., Kingstone, A., \& Schooler, J. W. (2013). 
The silver lining of a mind in the clouds: Interesting musings are associated with positive mood while mind-wandering. Frontiers in Psychology, 4, Art 583. https://doi.org/10.3389/fpsyg.2013.00583

32. Franklin, M. S., Smallwood, J., \& Schooler, J. W. (2011). Catching the mind in flight: using behavioral indices to detect mindless reading in real time. Psychonomic Bulletin \& Review, 18, 992-997. https:// doi.org/10.3758/s13423-011-0109-6

33. Fredrick, J. W., Luebbe, A. M., Mancini, K. J., Burns, G. L., Epstein, J. N., Garner, A. A., . . Becker, S. P. (2019). Family environment moderates the relation of sluggish cognitive tempo to attention deficit/ hyperactivity disorder inattention and depression. Journal of Clinical Psychology, 75(1), 221-237. https://doi.org/10.1002/jclp.22703

34. Giambra, L. M. (2000). Frequency and intensity of daydreaming: Age changes and age differences from late adolescent to the old-old. Imagination, Cognition and Personality, 19(3), 229-267. https:// doi.org/10.2190/XN4W-1CRE-B0MH-84XT

35. Giambra, L. M., \& Traynor, T. D. (1978). Depression and daydreaming; an analysis based on self-ratings. Journal of Clinical Psychology, 34(1), 14-25. https://doi.org/10.1002/10974679(197801)34:1<14::aid-jclp2270340103>3.0.co;2-\#

36. Giluk, T. L. (2009). Mindfulness, Big Five personality, and affect: A meta-analysis. Personality and Individual Differences, 47(8), 805-811. https://doi.org/10.1016/j.paid.2009.06.026

37. Heinz, W. R., Roberts, K., Goodwin, J., O’Connor, H., Du Bois-Reymond, M., Tanner, J. L., . . Furlong, A. (2009). Handbook of youth and young adulthood. London u.k: Routledge Ltd. https://doi. org/10.4324/9780203881965

38. Hoffmann, F., Banzhaf, C., Kanske, P., Bermpohl, F., \& Singer, T. (2016). Where the depressed mind wanders: Self-generated thought patterns as assessed through experience sampling as a state marker of depression. Journal of Affective Disorders, 198, 127-134. https://doi.org/10.1016/j. jad.2016.03.005

39. Irving, Z. C. (2016). Mind-wandering is unguided attention: Accounting for the "purposeful" wanderer. Philosophical Studies, 173(2), 547. https://doi.org/10.1007/s11098-015-0506-1

40. Jackson, P. B., \& Finney, M. (2002). Negative life events and psychological distress among young adults. Social Psychology Quarterly, 65(2), 186-201. https://doi.org/10.2307/3090100

41. Jarrett, M. A., Rapport, H. F., Rondon, A. T., \& Becker, S. P. (2017). ADHD dimensions and sluggish cognitive tempo symptoms in relation to self-report and laboratory measures of neuropsychological functioning in college students. Journal of Attention Disorders, 21(8), 673-683. https://doi. org/10.1177/1087054714560821

42. Jarrett, M., Siddiqui, S., Lochman, J., \& Qu, L. (2014) Internalizing problems as a predictor of change in externalizing problems in at-risk youth. Journal of Clinical Child \& Adolescent Psychology, 43(1), 27-35. https://doi.org/10.1080/15374416.2013.764823

43. Jonkman, L. M., Markus, C. R., Franklin, M. S., \& van Dalfsen, J. H. (2017). Mind wandering during attention performance: Effects of ADHD-inattention symptomatology, negative mood, ruminative response style and working memory capacity. PLoS ONE, 12(7), Art e0181213. https://doi.org/10.1371/ journal.pone.0181213

44. Kahneman, D., Krueger, A. B., Schkade, D. A., Schwarz, N., \& Stone, A. A. (2004). A survey method for characterizing daily life experience: The day reconstruction method. Science, 306(5702), 1776-1780. https://doi.org/10.1126/science.1103572

45. Kane, M. J., Brown, L. H., McVay, J. C., Silvia, P. J., Myin-Germeys, I., \& Kwapil, T. R. (2007). For whom the mind wanders, and when. Psychological Science, 18, 614-622. https://doi.org/10.1111/j.14679280.2007.01948.x 
46. Killingsworth, M. A., \& Gilbert, D. T. (2010). A wandering mind is an unhappy mind. Science, 330(6006), 932 . https://doi.org/10.1126/science.1192439

47. Klinger, E. C. (1999). Thought flow: Properties and mechanisms underlying shifts in content. In J. A. Singer \& P. Salovey (Eds.), At play in the fields of consciousness, Essays in honour of Jerome L. Singer (pp. 29-50). Mahwah, NJ: Erlbaum.

48. Kringlen, E., Torgersen, S., \& Cramer, V. (2001). A Norwegian psychiatric epidemiological study. American Journal of Psychiatry, 158, 1091-1098. https://doi.org/10.1176/appi.ajp.158.7.1091

49. Lee, Y., Chang, C., Lin, Y., \& Cheng, Z. (2014). The dark side of smartphone usage: Psychological traits, compulsive behavior and technostress. Computers in Human Behavior, 31, 373-383. https:// doi.org/10.1016/j.chb.2013.10.047

50. Leopold, D. R., Christopher, M. E., Burns, G. L., Becker, S. P., Olson, R. K., \& Willcutt, E. G. (2016). Attention deficit/hyperactivity disorder and sluggish cognitive tempo throughout childhood: Temporal invariance and stability from preschool through ninth grade. Journal of Child Psychology and Psychiatry, 57(9), 1066-1074. https://doi.org/10.1111/jcpp.12505

51. Maillet, D., Beaty, R. E., Jordano, M. L., Touron, D. R., Adnan, A., Silvia, P. J., . . Kane, M. J. (2018). Age-related differences in mind-wandering in daily life. Psychology and Aging, 33(4), 643-653. https://doi.org/10.1037/pag0000260

52. Mar, R. A., Mason, M. F., \& Litvack, A. (2012). How daydreaming relates to life satisfaction, loneliness, and social support: The importance of gender and daydream content. Consciousness and Cognition, 21(1), 401-407. https://doi.org/10.1016/j.concog.2011.08.001

53. Marchetti, I., Koster, E. H. W., \& De Raedt, R. (2012). Mindwandering heightens the accessibility of negative relative to positive thought. Consciousness and Cognition, 21(3), 1517-1525. https://doi. org/10.1016/j.concog.2012.05.013

54. Mason, M. F., Brown, K., Mar, R. A., \& Smallwood, J. (2013). Driver of discontent or escape vehicle: The affective consequences of mindwandering. Frontiers in Psychology, 4. https://doi.org/10.3389/ fpsyg.2013.00477

55. Matthews, G., Joyner, L., Gilliland, K., Huggins, J., \& Falconer, S. (1999). Validation of a comprehensive stress state questionnaire: Towards a state big three? In I. Merville, I. J. Deary, F. DeFruyt, \& F. Ostendorf (Eds.), Personality psychology in Europe (vol. 7, pp. 335-350). Tilburg: Tilburg University Press

56. Meyer, T. D., Finucane, L., \& Jordan, G. (2011). Is risk for mania associated with increased daydreaming as a form of mental imagery?. Journal of Affective Disorders, 135(1-3), 380-383. https://doi. org/10.1016/j.jad.2011.06.002

57. Moher, D., Liberati, A., Tetzlaff, J., Altman, D. G., \& Group, T. P. (2009). Preferred Reporting Items for Systematic Reviews and Meta-Analyses : The PRISMA Statement. PLoS Medicine, 6(7), e1000097. https://doi.org/10.1371/journal.pmed.1000097

58. Mooneyham, B. W., \& Schooler, J. W. (2013). The costs and benefits of mind-wandering. Canadian Journal of Experimental Psychology/Revue Canadienne De Psychologie Expérimentale, 67(1), 11-18. https://doi.org/10.1037/a0031569

59. Mowlem, F. D., Agnew-Blais, J., Pingault, J., \& Asherson, P. (2019). Evaluating a scale of excessive mind wandering among males and females with and without attention-deficit/hyperactivity disorder from a population sample. Scientific Reports, 9(1), 1-9. https://doi.org/10.1038/s41598-019-39227-w

60. Moylan, S., F. N. Jacka, J. A. Pasco, and M. Berk. (2012). Nicotine dependence, major depression, and anxiety in young adults. BMC Medicine, 10(1), 123. https://doi.org/10.1186/1741-7015-10-123

61. Mrazek, M. D., Phillips, D. T., Franklin, M. S., Broadway, J. M., \& Schooler, J. W. (2013). Young and rest- 
less: Validation of the mind-wandering questionnaire (MWQ) reveals disruptive impact of mind-wandering for youth. Frontiers in Psychology, 4, 560. https://doi.org/10.3389/fpsyg.2013.00560

62. Mrazek, M. D., Smallwood, J., \& Schooler, J. W. (2012). Mindfulness and mind wandering: Finding convergence through opposing constructs. Emotion, 12, 442- 448. https://doi.org/10.1037/a0026678_

63. Nes, R. B., Roysamb, E., Reichborn-Kjennerud, T., Harris, J. R., \& Tambs, K. (2007). Symptoms of anxiety and depression in young adults: Genetic and environmental influences on stability and change. Twin Research and Human Genetics, 10(3), 450-461. https://doi.org/10.1375/twin.10.3.450

64. Ostojic, D. (2018). Investigating mind wandering in university and community samples Available from Dissertations \& Theses Europe Full Text: Social Sciences. Retrieved from https://search.proquest. com/docview/2124630456

65. Poerio, G. L., Totterdell, P., \& Miles, E. (2013). Mind-wandering and negative mood: Does one thing really lead to another?. Consciousness \& Cognition, 22(4), 1412-1421. https://doi.org/10.1016/j.concog.2013.09.012

66. Pruzinsky, T., \& Borkovec, T. D. (1990). Cognitive and personality characteristics of worriers. Behaviour Research \& Therapy, 28(6), 507-512. https://doi.org/10.1016/0005-7967(90)90137-8

67. Raymond, C., Marin, M., Juster, R., Leclaire, S., Bourdon, O., Cayer-Falardeau, S., \& Lupien, S. J. (2019). Increased frequency of mind wandering in healthy women using oral contraceptives. Psychoneuroendocrinology, 101, 121-127. https://doi.org/10.1016/j.psyneuen.2018.11.005

68. Schupak, C., \& Rosenthal, J. (2009). Excessive daydreaming: A case history and discussion of mind wandering and high fantasy proneness. Consciousness and Cognition, 18(1), 290-292. https://doi. org/10.1016/j.concog.2008.10.002

69. Selby, E. A., Anestis, M. D., \& Joiner, T. E. J. (2007). Daydreaming about death: Violent daydreaming as a form of emotion dysregulation in suicidality. Behavior Modification, 31(6), 867-879. https://doi. org/10.1177/0145445507300874

70. Seli, P., Kane, M. J., Smallwood, J., Schacter, D. L., Maillet, D., Schooler, J. W., \& Smilek, D. (2018). Mind-wandering as a natural kind: A family-resemblances view. Trends in Cognitive Sciences, 22(6), 479-490. https://doi.org/10.1016/j.tics.2018.03.010

71. Seli, P., Risko, E., Purdon, C., \& Smilek, D. (2017). Intrusive thoughts: Linking spontaneous mind wandering and OCD symptomatology. Psychological Research, 81(2), 392-398. https://doi.org/10.1007/ s00426-016-0756-3

72. Seli, P., Risko, E. F., \& Smilek, D. (2016). Assessing the associations among trait and state levels of deliberate and spontaneous mind wandering. Consciousness and Cognition, 41, 50-56. https://doi. org/10.1016/j.concog.2016.02.002

73. Seli, P., Risko, E. F., Smilek, D., \& Schacter, D. L. (2016). Mind-Wandering With and Without Intention. Trends in cognitive sciences, 20(8), 605-617. https://doi.org/10.1016/j.tics.2016.05.010

74. Seli, P., Smallwood, J., Cheyne, J., \& Smilek, D. (2015). On the relation of mind wandering and ADHD symptomatology. Psychonomic Bulletin \& Review, 22(3), 629-636. https://doi.org/10.3758/s13423014-0793-0

75. Shrimpton, D., McGann, D., \& Riby, L. M. (2017). Daydream believer: Rumination, self-reflection and the temporal focus of mind wandering content. Europess Journal of Psychology, 13(4), 794-809. https://doi.org/10.5964/ejop.v13i4.1425

76. Singer, J. L. (1966). Daydreaming: An introduction to the experimental study of inner experience. New York, NY: Random House.

77. Singer, J. L., \& Antrobus, J. S. (1963). A factor-analytic study of daydreaming and conceptually-related cognitive and personality variables. Percept. Mot. Skills, 17, 187-209. https://doi.org/10.2466/ 
pms.1963.17.1.187

78. Smallwood, J. (2013). Distinguishing how from why the mind wanders: A process-occurrence framework for self-generated mental activity. Psychological Bulletin, 139, 519-535. https://doi. org/10.1037/a0030010

79. Smallwood, J. M., Baracaia, S. F., Lowe, M., \& Obonsawin, M. (2003). Task unrelated thought whilst encoding information. Consciousness and Cognition, 12(3), 452-484. https://doi.org/10.1016/S10538100(03)00018-7

80. Smallwood, J., \& O'Connor, R. C. (2011). Imprisoned by the past: Unhappy moods lead to a retrospective bias to mind wandering. Cognition \& Emotion, 25(8), 1481-1490. https://doi.org/10.1080/0269993 1.2010 .545263

81. Smallwood, J., \& Schooler, J. W. (2006). The restless mind. Psychological Bulletin, 132(6), 946-958. https://doi.org/10.1037/0033-2909.132.6.946

82. Smallwood, J., \& Schooler, J. W. (2015). The science of mind wandering: Empirically navigating the stream of consciousness. Annual Review of Psychology, 66(1), 487-518. https://doi.org/10.1146/annurev-psych-010814-015331

83. Smallwood, J., Fitzgerald, A., Miles, L. K., \& Phillips, L. H. (2009). Shifting moods, wandering minds: Negative moods lead the mind to wander. Emotion, 9(2), 271-276. https://doi.org/10.1037/a0014855

84. Smallwood, J., McSpadden, M., Luus, B., \& Schooler, J. W. (2008). Segmenting the stream of consciousness: The psychological correlates of temporal structures in the time series data of a continuous performance task. Brain and Cognition, 66, 50-56. https://doi.org/10.1016/j.bandc.2007.05.004

85. Smallwood, J., Riby, L., Heim, D., \& Davies, J. B. (2006). Encoding during the attentional lapse: Accuracy of encoding during the semantic sustained attention to response task. Consciousness and Cognition, 15(1), 218-231. doi:10.1016/j.concog.2005.03.003

86. Smallwood, J., Ruby, F. J. M., \& Singer, T. (2013). Letting go of the present: mind-wandering is associated with reduced delay discounting. Consciousness and Cognition, 22, 1-7. https://doi.org/10.1016/j. concog.2012.10.007

87. Tanner, J. L., \& Arnett, J. J. (2016). Emerging adult clinical psychology. In J. C. Norcross, G. R. VandenBos, D. K. Freedheim, \& M. M. Domenech Rodríguez (Eds.), APA handbooks in psychology. APA handbook of clinical psychology: Roots and branches (pp. 127-138). Washington, DC, US: American Psychological Association. https://doi.org/10.1037/14772-007

88. Vinski, M. T., \& Watter, S. (2013). Being a grump only makes things worse: A transactional account of acute stress on mind wandering. Frontiers in Psychology, 4, Art 730. https://doi.org/10.3389/ fpsyg.2013.00730

89. Wang, Y., \& Zhang, F. (2017). Trends in control and decision-making for human-robot collaboration systems. Cham, Switzerland: Springer.

90. Wang, Y., Xu, W., Zhuang, C., \& Liu, X. (2017). Does mind wandering mediate the association between mindfulness and negative mood? A preliminary study. Psychological Reports, 120(1), 118129. https://doi.org/10.1177/0033294116686036

91. West, S. G., \& Gunn, S. P. (1978). Some issues of ethics and social psychology. American Psychologist, 33(1), 30-38. https://doi.org/10.1037/0003-066X.33.1.30

92. Whitelaw, C. (2016). Developing an inclusive perspective for a diverse college: Inclusion = diversity + engagement. Integral Review, 12(1), 32-64.

93. Willcutt, E., Chhabildas, N., Kinnear, M., DeFries, J., Olson, R., Leopold, D., . . Pennington, B. (2014). The internal and external validity of sluggish cognitive tempo and its relation with DSM-IV ADHD. Journal of Abnormal Child Psychology, 42(1), 21-35. https://doi.org/10.1007/s10802-013- 
9800-6

94. Wood, W. L. M., Lewandowski, L. J., Lovett, B. J., \& Antshel, K. M. (2017). Executive dysfunction and functional impairment associated with sluggish cognitive tempo in emerging adulthood. Journal of Attention Disorders, 21(8), 691-700. https://doi.org/10.1177/108705471456082

95. Xu, M., Purdon, C., Seli, P., \& Smilek, D. (2017). Mindfulness and mind wandering: The protective effects of brief meditation in anxious individuals. Consciousness and Cognition, 51, 157-165. https:// doi.org/10.1016/j.concog.2017.03.009 